GANIT J. Bangladesh Math. Soc. (ISSN 1606-3694) 37 (2017) 131-145

\title{
SIMULATION OF THERMODYNAMIC FEATURES OF A THUNDERSTORM EVENT OVER DHAKA USING WRF-ARW MODEL
}

\author{
Md. Mijanur Rahman ${ }^{1 *}$, Md. Abdus Samad ${ }^{1}$, S. M. Quamrul Hassan ${ }^{2}$ \\ ${ }^{1}$ Department of Applied Mathematics, University of Dhaka, Dhaka, Bangladesh \\ ${ }^{2}$ Bangladesh Meteorological Department, Agargaon, Dhaka, Bangladesh \\ *Corresponding author: mijanur.du10@gmail.com
}

Received 05.07.2017 Accepted 26.10.2017

\begin{abstract}
An attempt has been made to simulate the thermodynamic features of the thunderstorm (TS) event over Dhaka $\left(23.81^{\circ} \mathrm{N}, 90.41^{\circ} \mathrm{E}\right)$ occurred from 1300 UTC to 1320 UTC of 4 April 2015 using Advanced Research dynamics solver of Weather Research and Forecasting model (WRF-ARW). The model was run to conduct a simulation for 48 hours on a single domain of $5 \mathrm{~km}$ horizontal resolution utilizing six hourly Global Final Analysis (FNL) datasets from 0600 UTC of 3 April 2015 to 0600 UTC of 5 April 2015 as initial and lateral boundary conditions. Kessler schemes for microphysics, Yonsei University (YSU) scheme for planetary boundary layer (PBL) parametrization, Revised MM5 scheme for surface layer physics, Rapid Radiative Transfer Model (RRTM) for longwave radiation, Dudhia scheme for shortwave radiation and Kain-Fritsch (KF) scheme for cumulus parameterization were used. Hourly outputs produced by the model have been analyzed numerically and graphically using Grid Analysis and Display System (GrADS). Deep analyses were carried out by examining several thermodynamic parameters such as mean sea level pressure (MSLP), wind pattern, vertical wind shear, vorticity, temperature, convective available potential energy (CAPE), relative humidity (RH) and rainfall. To validate the model performance, simulated values of MSLP, maximum and minimum temperature and RH were compared with observational data obtained from Bangladesh Meteorological Department (BMD). Rainfall values were compared with that of BMD and Tropical Rainfall Measuring Mission (TRMM) of National Aeronautics and Space Administration (NASA). Based on the comparisons and validations, the present study advocates that the model captured the TS event reasonably well.
\end{abstract}

Keywords: Thunderstorm, WRF-ARW Model, FNL, CAPE.

\section{Introduction}

The Earth's atmosphere is majestic in its beauty, awesome in its power, and complex in its behavior. And thunderstorm (TS), resulting from vigorous convective activity, is one of the most devastating, yet spectacular, weather phenomena in it. TS is characterized by lightning and thunder and associated with stormy winds, heavy rainfall, hail and tornadoes. It can occur almost everywhere in the world and cause mass destruction to properties and lives. Thunderstorms are very common over Bangladesh $\left(20^{\circ} 34^{\prime} \mathrm{N}\right.$ 
to $26^{\circ} 38^{\prime} \mathrm{N}$ and $88^{\circ} 01^{\prime} \mathrm{E}$ to $92^{\circ} 41^{\prime} \mathrm{E}$ ) during the premonsoon season. These storms are locally known as 'Kalbaishakhi' in Bengali because of the heavy damage to life and property inflicted by them during the month of 'Baishakh' - the first month of Bengali calendar (from mid-April to mid-May). Bangladesh has an estimate of 60-100 TS days per year [1]. According to Habib [2], TS is ranked 3rd in the list of hazards that affect Bangladesh.

Forecasting thunderstorms is one of the most difficult tasks in weather prediction, due to their rather small spatial and temporal extension and the inherent non-linearity of their dynamics and physics. The use of Numerical Weather Prediction (NWP) system to complement the interpretation of conventional observations added great value to TS forecasting. The physics and the dynamics of TS can be understood by simulating these systems with the help of mesoscale models. Simulation of TS with highresolution mesoscale models over the Indo-Bangla region has mainly been attempted in the past ten years [3-11]. A simulation study was carried out by Vaidya [3] for a pre-monsoon thunderstorm over east coast of India. Mesoscale model MM5 with some modifications in the cloud microphysics scheme of Schultz has been used to simulate two hailstorm events over the Gangetic Plain of West Bengal by Chatterjee et al. [4]. The authors found that the model MM5 has the ability to simulate hailstorm if the cloud microphysics scheme of Schultz is modified suitably. Litta and Mohanty [5] performed a simulation of a severe thunderstorm event using WRF-NMM model. Rajeevan et al. [6] simulated the features associated with a severe thunderstorm event over Gadanki (over southeast India) using WRF model and examined its sensitivity to four different microphysics (MP) schemes validated with many observations. This study showed large sensitivity of the microphysics schemes in the simulations of the thunderstorm. Das et al. [7] studied the sensitivity with physical parameterization schemes of WRFARW model in the simulation of mesoscale convective systems associated with squall events. Thunderstorm simulations from WRF-NMM and WRF-ARW Models were compared by Litta et al. [8]. Ahasan et al. [9] carried out a simulation of the TS event over Srimangal, Bangladesh at 1200 UTC on 21 May 2011 using WRF-ARW model. They found that the model overestimated the 24-hour rainfall over the country by $46.72 \%$ compared to the rainfall amounts recorded by Bangladesh Meteorological Department (BMD). Ahasan and Debsarma [10] studied the impact of data assimilation in simulation of the thunderstorm (squall line) event of 11 May 2011 over Bangladesh using WRF model.

In this paper, the thermodynamic features of the TS event occurred over Dhaka $\left(23.81^{\circ} \mathrm{N}, 90.41^{\circ} \mathrm{E}\right)$ from 1310 UTC to 1320 UTC of 4 April 2015 have been studied by analyzing eight parameters: MSLP, wind flow, vertical wind shear, vorticity, temperature, CAPE, RH and rainfall. Wind flow was analyzed at two pressure levels: 850 and $200 \mathrm{hPa}$ (hectopascal). Vertical wind shear was measured between 200 and $850 \mathrm{hPa}$ level. Vorticity was simulated at $500 \mathrm{hPa}$ level. RH was analyzed in two ways: (i) RH at $2 \mathrm{~m}$ height from surface was simulated over the considered domain and (ii) Vertical cross section of RH from $1000 \mathrm{hPa}$ to $100 \mathrm{hPa}$ level was simulated along the latitude of Dhaka (23.81 $\left.{ }^{\circ} \mathrm{N}\right)$. Hourly rainfall during the event was simulated along with the comparison of 24-hour rainfall of 04 April 2015. 


\section{Synoptic Condition of the TS Event}

A trough of westerly low was observed over West-Bengal and adjoining Bangladesh on Saturday, 04 April 2015. According to BMD, a TS struck Dhaka between 1300 and 1320 UTC. At 1200 UTC, Mean Sea Level Pressure (MSLP) was recorded by BMD to be $1001.3 \mathrm{hPa}$ over Dhaka. From 1300 UTC to 1320 UTC, very strong northwesterly wind having a maximum speed of 107 $\mathrm{km} / \mathrm{h}$ was observed over this area. Rainfall amount of $30 \mathrm{~mm}$ (millimeter) was recorded by BMD at Dhaka station on this day.

\section{Data and Methodology}

In this study, six-hourly Global Final Analysis (FNL) datasets from 0600UTC of 3 April 2015 to 0600UTC of 05 April 2015 prepared by National Center for Environmental Prediction (NCEP) are used as the initial and lateral boundary conditions. These data are on $1^{\circ}$ by $1^{\circ}$ grid prepared operationally every six hours from the Global Data Assimilation System (GDAS), which continuously collects observational data from the Global Telecommunications System (GTS), and other sources, for many analyses. The analyses are available on the surface, at 26 mandatory (and other pressure) levels from 1000 millibars to 10 millibars, in the surface boundary layer and at some sigma layers, the tropopause and a few others. On the other hand, available observations of MSLP, maximum and minimum temperature, RH and daily rainfall of the event day have been collected from the archive of BMD to validate the model derived simulation. Rainfall data were also collected from the Tropical Rainfall Measuring Mission (TRMM) of National Aeronautics and Space Administration (NASA).

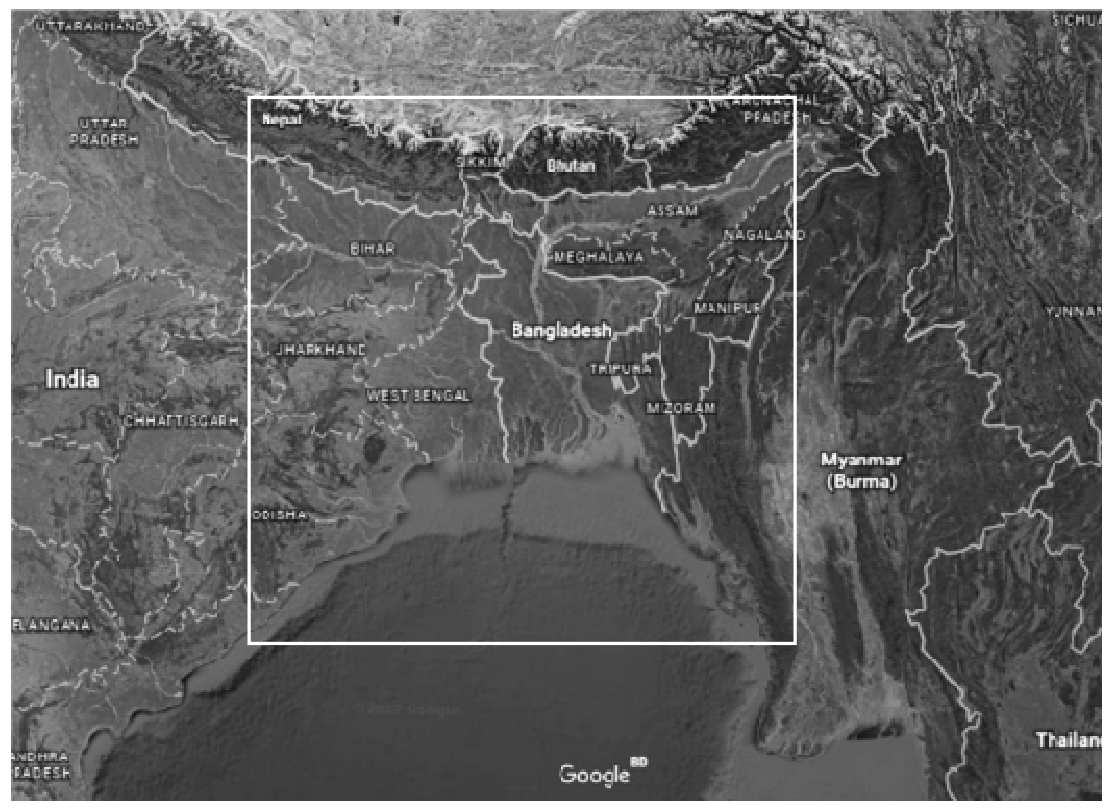

Fig. 1: Domain considered for this case study. 
The WRF model is a non-hydrostatic mesoscale model developed for simulation and prediction of atmospheric phenomena of different scales of dynamics of the atmosphere, emphasizing horizontal grid lengths of a few kilometers or less [11]. It has two dynamics solvers: Advanced Research WRF (ARW) and Nonhydrostatic Mesoscale Model (NMM). ARW (version 3.8.0) developed by the National Center for Atmospheric Research (NCAR) [12] is implemented during this study. The domain $\left(18^{\circ} \mathrm{N}\right.$ to $28.5^{\circ} \mathrm{N}$ and $84^{\circ} \mathrm{E}$ to $\left.96^{\circ} \mathrm{E}\right)$ of this study is shown in Figure 1 . The center of the domain was taken to be $23.5^{\circ} \mathrm{N} \& 90^{\circ} \mathrm{E}$.

The WRF-ARW model offers quite a good number of schemes for the investigation of different physics such as microphysics, planetary boundary layer (PBL) physics, radiation physics and cumulus parametrization (CU). Details of the configurations that were chosen to run the model during this study are given in Table 1 .

Table 1: Overview of WRF model configurations

\begin{tabular}{|c|c|c|}
\hline \multicolumn{3}{|c|}{ Domain \& Dynamics } \\
\hline WRF core & $:$ & ARW \\
\hline Data & $:$ & NCEP-FNL \\
\hline Input data interval & $:$ & $6 \mathrm{~h}$ \\
\hline Output data interval & $:$ & $1 \mathrm{~h}$ \\
\hline Number of domain & $:$ & 1 \\
\hline Central point of the domain & $:$ & $23.5^{\circ} \mathrm{N}, 90^{\circ} \mathrm{E}$ \\
\hline Resolution & $:$ & $5 \mathrm{~km} \times 5 \mathrm{~km}$ \\
\hline Grid size & : & $\begin{array}{l}267 \times 233 \times 40 \text { (total } 24,88,440 \text { grid } \\
\text { points at each time step) }\end{array}$ \\
\hline Covered area & $:$ & $18^{\circ}$ to $28.5^{\circ} \mathrm{N}$ and $84^{\circ}$ to $96^{\circ} \mathrm{E}$ \\
\hline Map projection & $:$ & Mercator \\
\hline Integration time step & $:$ & $30 \mathrm{~s}$ \\
\hline Vertical coordinates & $:$ & Pressure coordinate \\
\hline Time integration scheme & $:$ & 3rd order Runge-Kutta \\
\hline Spatial differencing scheme & $:$ & 6th order centered difference \\
\hline \multicolumn{3}{|r|}{ Physics } \\
\hline Microphysics & $:$ & Kessler scheme \\
\hline PBL Parameterization & $:$ & Yonsei University (YSU) scheme \\
\hline Surface layer physics & : & Revised MM5 scheme \\
\hline Land-surface model & $:$ & Unified Noah LSM \\
\hline Short wave radiation & $:$ & Dudhia scheme \\
\hline Long wave radiation & $:$ & RRTM scheme \\
\hline Cumulus parameterization & : & Kain-Fritsch (new Eta) scheme \\
\hline
\end{tabular}




\section{Governing Equations}

The basic form of the atmospheric governing equations are as follows:

$$
\begin{aligned}
& \frac{d \boldsymbol{U}}{d t}=-\frac{1}{\rho} \boldsymbol{\nabla} p+\boldsymbol{g}+\boldsymbol{F}-2 \boldsymbol{\Omega} \times \boldsymbol{U} \\
& \frac{\partial \rho}{\partial t}=-\boldsymbol{\nabla} \cdot(\rho \boldsymbol{U}) \\
& p=\rho R T \\
& c_{p} \frac{d \ln T}{d t}-R \frac{d \ln p}{d t}=\frac{J}{T}=\frac{d s}{d t} \\
& \frac{d q}{d t}=E-C
\end{aligned}
$$

Equation (1) is the vectorial form of the momentum equation that states Newton's second law for motion relative to a rotating coordinate frame. Here, $\boldsymbol{U}=(u, v, w)$ is the velocity vector relative to the rotating frame, $\rho$ is the density, $p$ denotes pressure, $\boldsymbol{g}$ is the acceleration due to gravity, $\boldsymbol{F}$ represents the frictional force and centrifugal force combinedly and $\boldsymbol{\Omega}$ is the angular velocity of the rotating frame. This equation states that the acceleration following the relative motion in the rotating frame equals the sum of the Coriolis force, the pressure gradient force, gravity, frictional and centrifugal force. In case of spherical coordinate system, equation (1) can be decomposed into the following three equations:

$$
\begin{aligned}
& \frac{d u}{d t}-\frac{u v \tan \phi}{a}+\frac{u w}{a}=-\frac{1}{\rho} \frac{\partial p}{\partial x}+2 \Omega v \sin \phi-2 \Omega w \cos \phi+F_{x} \\
& \frac{d v}{d t}+\frac{u^{2} \tan \phi}{a}+\frac{v w}{a}=-\frac{1}{\rho} \frac{\partial p}{\partial y}-2 \Omega u \sin \phi+F_{y} \\
& \frac{d w}{d t}-\frac{u^{2}+v^{2}}{a}=-\frac{1}{\rho} \frac{\partial p}{\partial z}-g+2 \Omega u \cos \phi+F_{z}
\end{aligned}
$$

In these equations, $a$ is the mean radius of Earth while $\phi$ denotes the latitude. Equations (6), (7) and (8) are respectively the eastward, northward and vertical component of the momentum equation (1).

Equation (2) is the continuity equation which expresses the conservation of mass. It states that the local rate of change of density is equal to the convergence of mass.

Equation (3) is called the equation of state (or ideal gas law) for dry air. In this equation, $T$ denotes the temperature while $R$ is the gas constant whose value for dry air is $287 \mathrm{~J} \mathrm{~kg}^{-1} \mathrm{~K}^{-1}$.

In equation (4), $c_{p}$ is the specific heat at constant pressure, $s$ designates entropy and $J$ is the rate of heating per unit mass due to radiation, conduction and latent heat release. This equation is a modified form of the thermodynamic energy equation (TDE): 


$$
c_{v} \frac{d T}{d t}+p \frac{d a}{d t}=J
$$

where $c_{v}$ is the specific heat at constant volume and $\alpha=\frac{1}{\rho}$ is the specific volume. The modified form (8) of equation (9) indicates that vertical motion in the atmosphere changes the thermodynamic state in a reversible way. A parcel moving vertically will change temperature due to compression or expansion with pressure change, but when returned to its original level, it will have done no work on its environment. If $J=0$, then its temperature will return to the original temperature.

Equation (5) is the simplified form of the conservation of moisture. It states that the rate of change of moisture following the motion of an air parcel $\left(\frac{d q}{d t}\right)$ is equal to the difference between evaporation-sublimation $(E)$ and condensation $(C)$.

The ARW dynamics solver integrates the compressible, non-hydrostatic Euler equations. The equations are cast in flux form using variables that have conservation properties, following the philosophy of Ooyama [13] and formulated using a terrain-following mass vertical coordinate [14]. Then they are extended to include the effects of moisture, Coriolis and curvature terms and further augmented to include projections to the sphere. Finally, before constructing the discrete solver, the governing equations are recast to perturbation form using perturbation variables to reduce truncation errors in the horizontal pressure gradient calculations and machine rounding errors in the vertical pressure gradient and buoyancy calculations.

\section{Simulation and Analysis}

\subsection{Analysis of MSLP}

Model-simulated MSLP of 04 April 2015 from 1200 UTC to 1400 UTC of 04 April 2015 at 1-hour interval based on the initial conditions of 0600 UTC of 03 April 2015 are shown in Figure 2 (a-c).

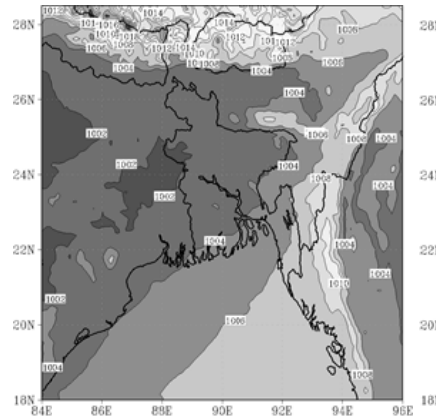

(a) 1200 UTC

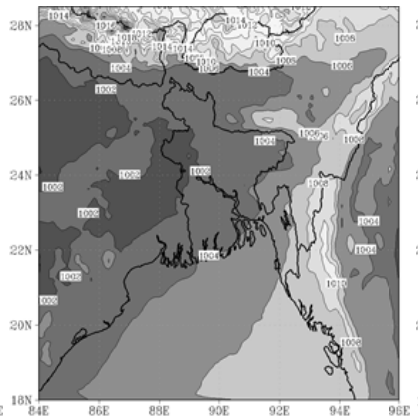

(b) 1300 UTC

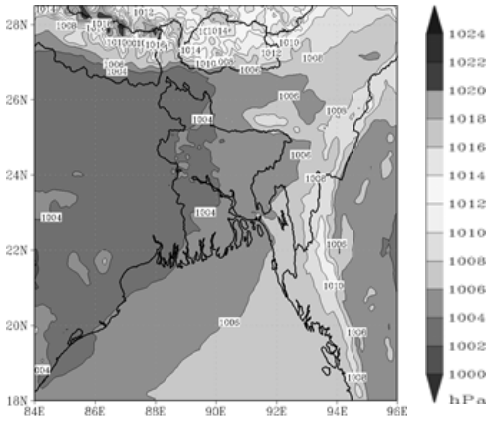

(c) 1400 UTC

Fig. 2: Model-simulated MSLP based on 0600 UTC of 03 April 2015 initial conditions.

It is found that at 1200 UTC, a trough of westerly low (1000-1002 hPa) is simulated over West Bengal and adjoining part of Rajshahi. MSLP over Dhaka is found to be $1002-1004 \mathrm{hPa}$ at this 
time. Higher MSLP is found over the eastern side of Bangladesh. At 1300 UTC, MSLP is simulated to be in the same range as before. But at 1400 UTC, MSLP is simulated to rise up to $1006 \mathrm{hPa}$. This implies a sudden drop in MSLP during 1200 UTC to 1300 UTC which is supportive for the formation of any convective phenomenon.

For validation of the model performance, MSLP values at 0000 UTC, 0600 UTC, 1200 UTC and 1800 UTC of 04 April 2015 simulated by the model were compared with that of BMD records over Dhaka. Figure 3 shows the comparison.

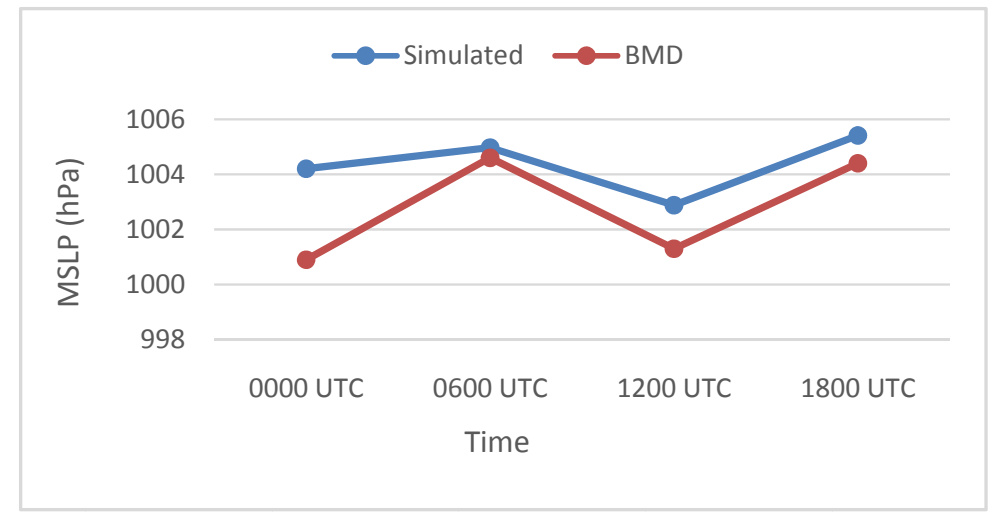

Fig. 3: Comparison of MSLP of 04 April 2015.

\subsection{Analysis of Wind Flow}

The model simulated wind was analyzed at two pressure levels: $850 \mathrm{hPa}$ and $200 \mathrm{hPa}$. Figure 4 (ab) shows the model simulated wind patterns at 1300 UTC at these levels.

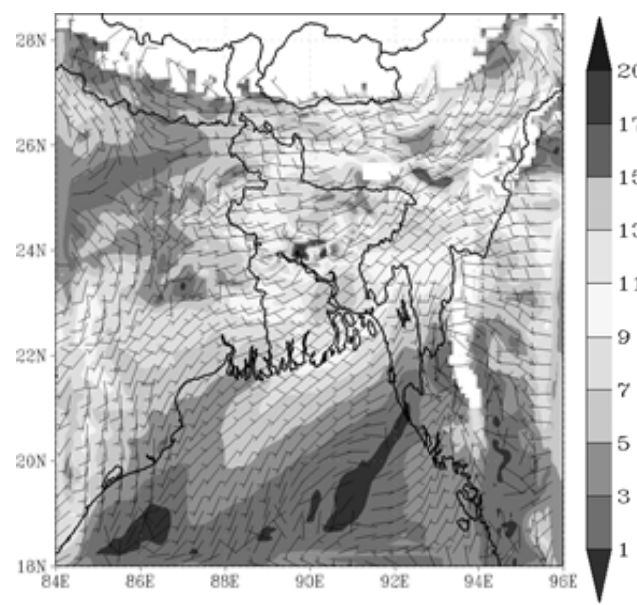

(a) At $850 \mathrm{hPa}$ level

$\mathrm{m} / \mathrm{s}$

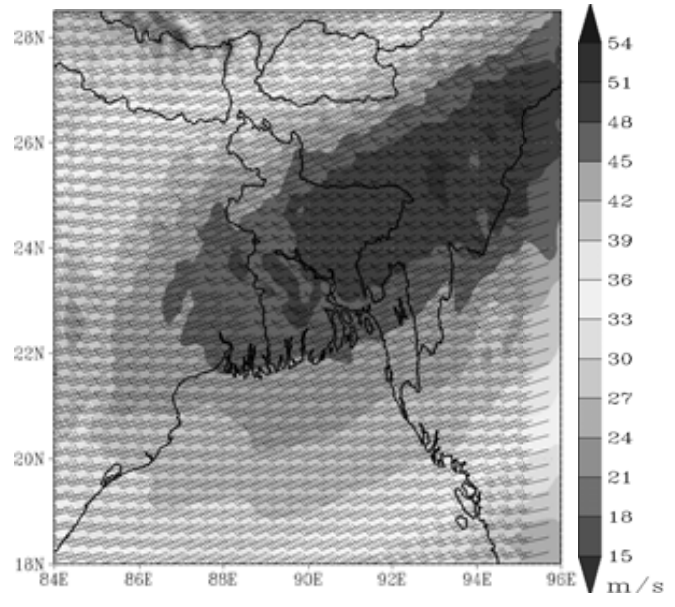

(b) At $200 \mathrm{hPa}$ level

Fig. 4: Model-simulated wind patterns at 1300 UTC of 04 April 2015 based on 0600 UTC of 03 April 2015 initial conditions. 
At $850 \mathrm{hPa}$ level, a convergence zone of very high wind speed $\left(15-20 \mathrm{~ms}^{-1}\right)$ is simulated over Dhaka and its western areas which is a strong indication of severe weather phenomena. At $200 \mathrm{hPa}$ level, southwesterly wind is blowing with a speed of order $48-51 \mathrm{~ms}^{-1}$ over Dhaka. This indicates very good vertical wind shear and divergence in the upper level causing the breakdown of further vertical extension of the system.

\subsection{Analysis of Vertical Wind Shear}

Vertical wind shear is the difference, at the same geographical coordinates, but at different altitudes, in the direction or strength of winds. It is the one of the most critical factors in the determination of thunderstorm potential and severity since it interacts dynamically with thunderstorms to either enhance or diminish vertical draft strengths. Meteorologists typically refers to the difference in wind speed between $200 \mathrm{hPa}$ and $850 \mathrm{hPa}$ levels. Despite the fact that the 200$850 \mathrm{hPa}$ wind shear is a crude measure of the actual wind shear since only changes in wind speed not wind direction - are considered, it works fine as a parameter to determine the possible formation and severity of TS.

Model-simulated 200-850 hPa vertical wind shear from 1200 UTC to 1400 UTC of 04 April 2015 at 1-hour interval based on 0600 UTC of 03 April 2015 initial conditions are shown in Figure 5 (ac). A small zone having large amount of shear (40-45 ms-1) is simulated over Dhaka and adjoining areas at 1200 UTC and 1300 UTC. This high value of vertical wind shear allows the updraft to sustain for long duration. Moreover, strong upper tropospheric wind (found in the analysis of wind pattern) evacuates mass from the top of the updraft which is very much supportive for the formation of severe TS. In the next hour, vertical wind shear is simulated to be decreasing over this region.

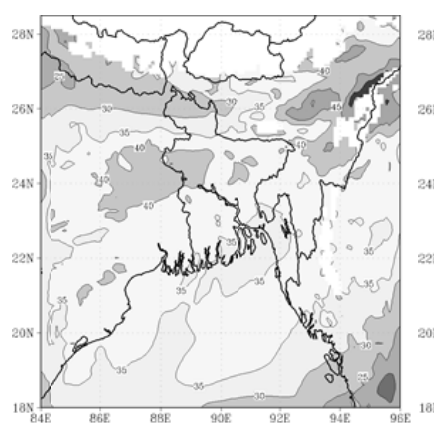

(a) 1200 UTC

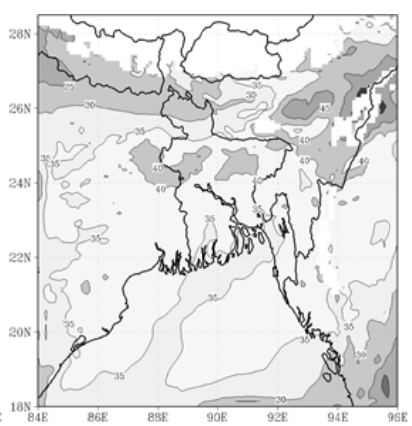

(b) 1300 UTC

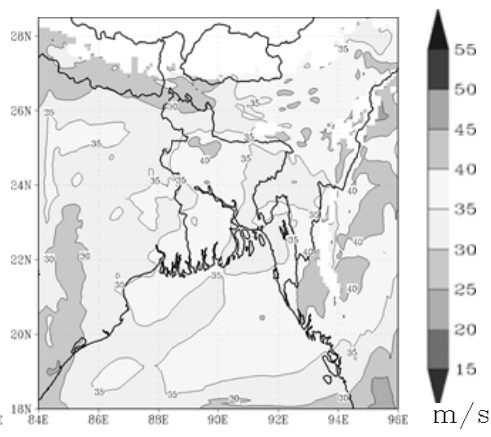

(c) 1400 UTC

Fig. 5: Model-simulated 200-850 hPa vertical wind shear based on 0600 UTC of 03 April 2015 initial conditions.

\subsection{Analysis of Vorticity}

Vorticity is a measure of the spin of air parcels. Meteorologists are mostly concerned with the spin of horizontally flowing air about a vertical axis. So, the term 'vorticity' usually refers to the 
vertical component of the curl of the wind. Mode-simulated vorticity at $500 \mathrm{hPa}$ level from 1200 UTC to 1400 UTC of 04 April 2015 at 1-hour interval based on 0600 UTC of 03 April 2015 initial conditions are shown in Figure 6 (a-c).

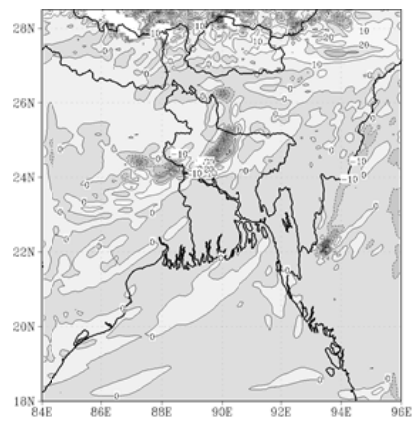

(a) 1200 UTC

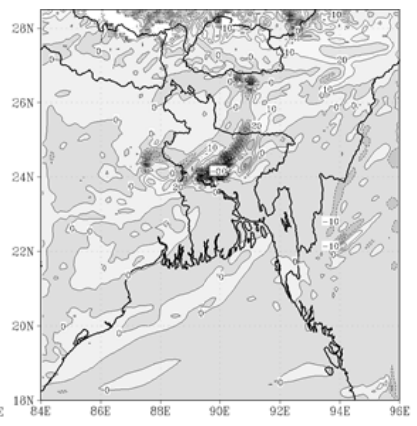

(b) 1300 UTC

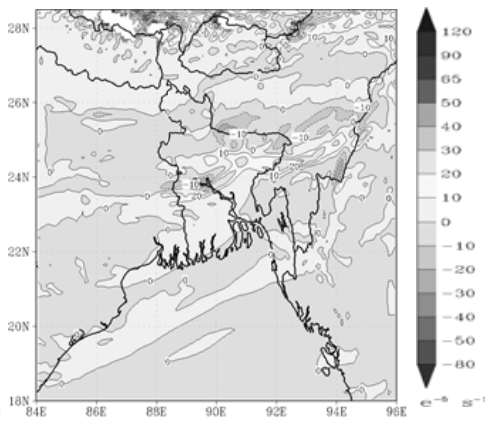

(c) 1400 UTC

Fig. 6: Model-simulated vorticity at $500 \mathrm{hPa}$ level based on 0600 UTC of 03 April 2015 initial conditions.

At 1200 UTC, two adjacent zones of positive vorticity (30×10-5 s-1 to $40 \times 10-5 \mathrm{~s}-1)$ and negative vorticity $(-30 \times 10-5$ s-1 to $-20 \times 10-5 s-1)$ are simulated over the northwest areas of Dhaka. In the next hour, vorticity maximum and minimum, both of very high magnitude are found over Dhaka and adjoining areas. This indicates strong rotating updrafts associated with rising air and heavy downdrafts associated with sinking air that may occur simultaneously which is very much supportive for the formation of TS. At 1400 UTC, vorticity is simulated to be decreasing down to zero over Dhaka.

\subsection{Analysis of Temperature}

Temperature plays a vital role in the formation of TS. When the temperature of some particular area becomes higher than the surroundings, low pressure system can originate there and cooler air from the surroundings tends to flow towards that region resulting in the development of a convergence zone. Model-simulated temperature at 2m height from 1200 UTC to 1400 UTC of 04 April 2015 at 1-hour interval based on 0600 UTC of 03 April initial conditions are shown in Figure 7 (a-c).

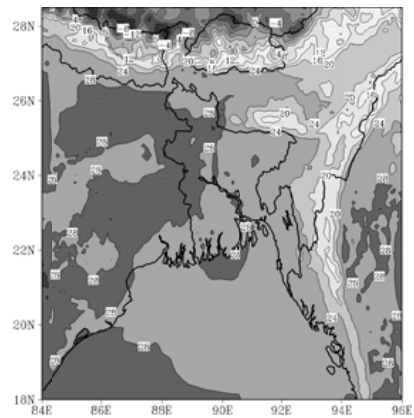

(a) 1200 UTC

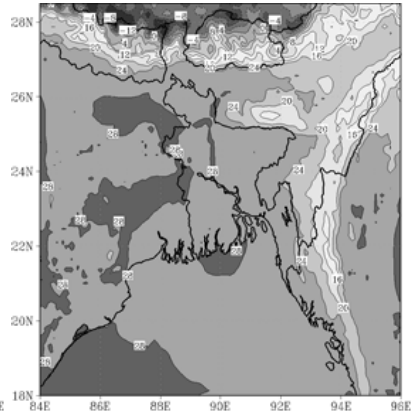

(b) 1300 UTC

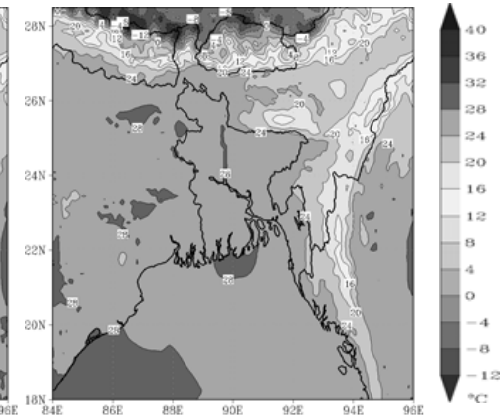

(c) 1400 UTC

Fig. 7: Model-simulated temperature at 2m height based on 0600 UTC of 03 April 2015 initial conditions. 
It is found that, $32-36{ }^{\circ} \mathrm{C}$ temperature is simulated over West-Bengal and adjoining western part of Bangladesh including some areas of Dhaka at 1200 UTC, while the eastern part of Bangladesh is simulated to have a temperature between 28 and $32{ }^{\circ} \mathrm{C}$. This means that there exists a temperature gradient over these regions. Since the updraft mechanism in the warmer zone is strong due to high vertical wind shear (found in the analysis of vertical wind shear), cumulonimbus cloud formation is favorable. Temperature is found to fall down gradually over the next two hours resulting an estimation of $24-28^{\circ} \mathrm{C}$ temperature at 1400 UTC over Dhaka. Figure 8 shows the comparison of model-simulated maximum and minimum temperature values of 04 April 2015 with that of BDM records.

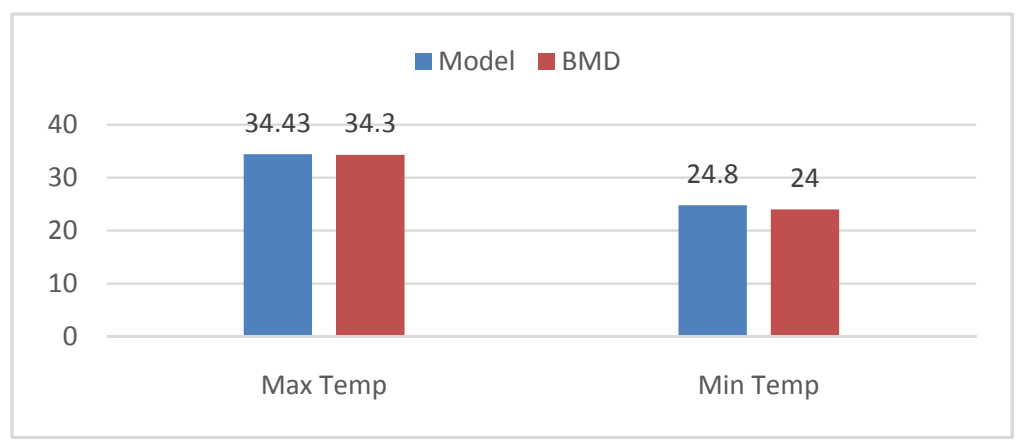

Fig. 8: Comparison of maximum and minimum temperature of 04 April 2015.

From Figure 8, it is seen that the model slightly overestimated both the maximum and minimum temperature.

\subsection{Analysis of CAPE}

CAPE is the short form of 'Convective Available Potential Energy'. Simply speaking, it is a measure of the amount of energy available for convection. Mathematically, CAPE is calculated by integrating vertically the local buoyancy of a parcel from the level of free convection (LFC) to the equilibrium level (EL) and according to American Meteorological Society [15], it is given by the following formula:

$$
C A P E=\int_{p_{f}}^{p_{n}} R_{d}\left(T_{v p}-T_{v e}\right) d \ln p
$$

where $T_{v p}$ is the virtual temperature of a lifted parcel moving upward moist adiabatically from $\mathrm{LFC}$ to EL, $T_{v e}$ is the virtual temperature of the environment, $R_{d}$ is the specific gas constant for dry air, $p_{f}$ is the pressure at LFC, and $p_{n}$ is the pressure at EL. Virtual temperature is the temperature that dry air would have if its pressure and density were equal to those of a given sample of moist air. Also, it is assumed that the environment is in hydrostatic balance, i.e., $\frac{d p}{d z}=-\rho g$ holds and that the pressure of the parcel is the same as that of the environment. CAPE is measured in $\mathrm{J} / \mathrm{kg}$. It plays a vital role in detecting the possibility of TS as it represents the amount 
of buoyant energy available to speed up a parcel vertically. Higher values of CAPE indicate greater potential for severe weather. In a highly unstable atmosphere, CAPE values are usually in excess of $2500 \mathrm{~J} / \mathrm{kg}$ which would supply ample energy for strong updrafts and violent thunderstorms should they develop.

Model-simulated CAPE at 850 hPa level from 1200 UTC to 1400 UTC of 04 April 2015 at 1-hour interval based on 0600 UTC of 03 April 2015 initial conditions are shown in Figure 9 (a-c).

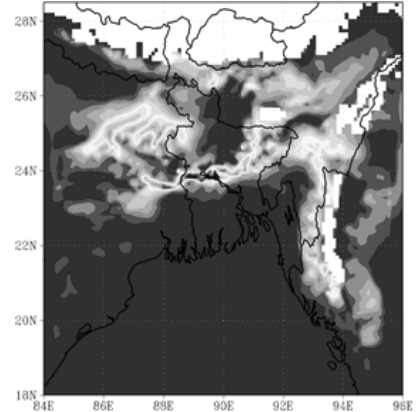

(a) 1200 UTC

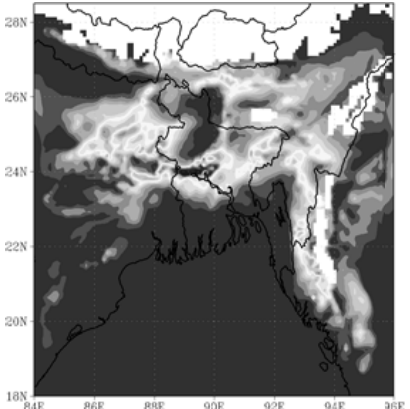

(b) 1300 UTC

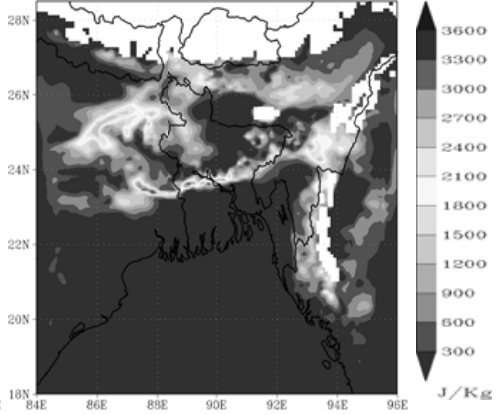

(c) 1400 UTC

Fig. 9: Model-simulated CAPE at 850 hPA level based on 0600 UTC of 03 April 2015 initial conditions.

At 1200 UTC, 2400-3000 J/kg CAPE is simulated over Dhaka. A narrow zone of extreme CAPE values (3300-3600 J/kg) is found to the west of Dhaka. At $1300 \mathrm{UTC}$, CAPE is simulated to be increasing up to $3600 \mathrm{~J} / \mathrm{kg}$ over these areas which is a strong indication of unstable weather and possible TS formation. CAPE is simulated to be decreased during the next hour.

\subsection{Analysis of $R H$}

Relative humidity (RH) is a very important factor for the detection of cloud and rainfall. Modelsimulated RH at 2m height from 1200 UTC to 1400 UTC of 04 April 2015 at 1-hour interval based on 0600 UTC of 03 April 2015 initial conditions are shown in Figure 10 (a-c).

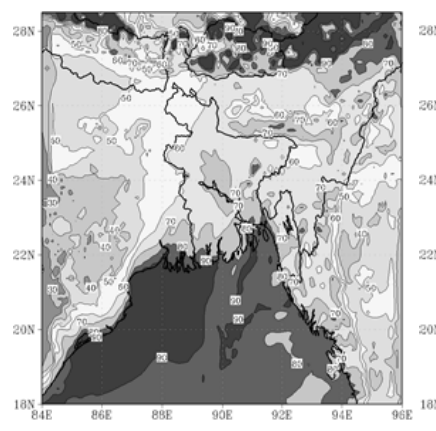

(a) 1200 UTC

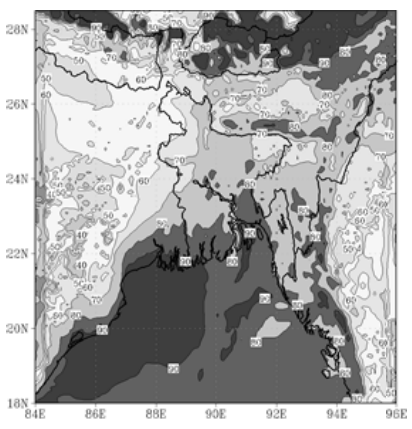

(b) 1300 UTC

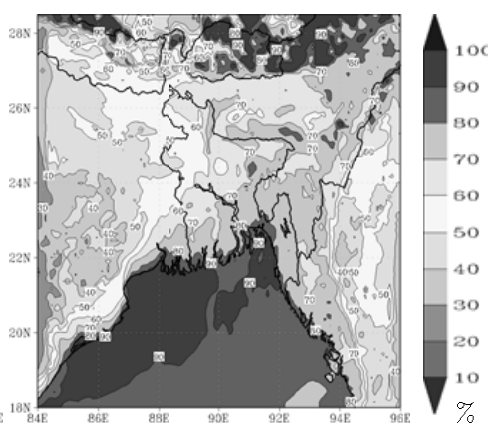

(c) 1400 UTC

Fig. 10: Model-simulated RH at 2m height based on 0600 UTC of 03 April 2015 initial conditions. 
At 1200 UTC, RH over West-Bengal and adjoining areas of Rajshahi division is simulated to be less than $60 \%$. Over the middle and eastern part of Bangladesh, RH is greater than $60 \%$. The contour line representing $60 \% \mathrm{RH}$ is regarded as the 'dry line'. In the dry sector (west of the dry line), clear sky is the rule due to the dryness of the air masses while cumulus clouds are common in the moist sector (east of the dry line). $70-80 \% \mathrm{RH}$ is simulated over Dhaka at this time. In the next hour, $\mathrm{RH}$ is found to rise up to $90 \%$ over some areas of Dhaka. At $1400 \mathrm{UTC}$, RH is simulated to be decreased over those areas. This whole scenario is a strong indication of cumulonimbus cloud formation in the earlier hours and then precipitation afterwards.

Vertical cross section of RH is more helpful in this regard. Model-simulated vertical cross section of RH between 1000 and $100 \mathrm{hPa}$ levels along 23.81 $\mathrm{N}$ (latitude of Dhaka) at $1300 \mathrm{UTC}$ of 04 April 2015 based on 0600 UTC of 03 April 2015 initial conditions is shown in Figure 11. The model simulated a vertical column of RH $80-100 \%$ over Dhaka and adjoining eastern areas. This column is well organized and looks like a towering cumulonimbus cloud. Also, a small zone in this column between 400 and $300 \mathrm{hPa}$ levels has RH above 100\%. It indicates possible rainfall and hail formation which is very much favorable to the occurrence of TS over these areas.

For validation, model-simulated average value of RH of 04 April 2015 over Dhaka is compared with that of BDM observation. Figure 12 shows this comparison.

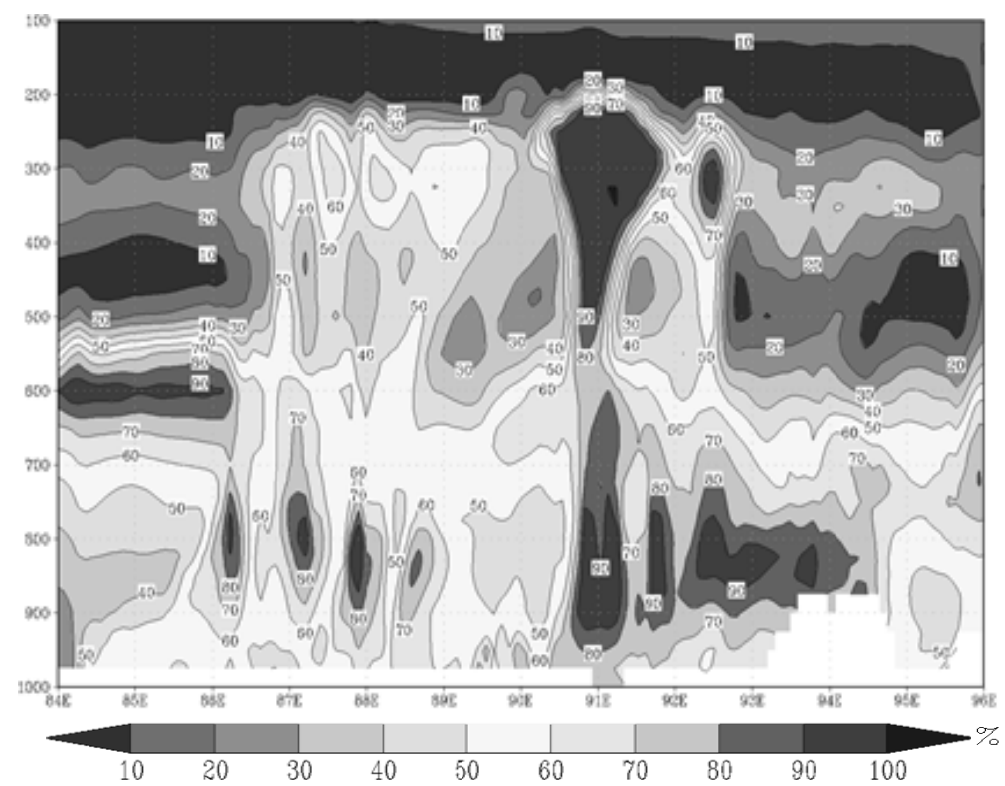

Fig. 11: Model-simulated vertical cross section of RH along $23.81^{\circ} \mathrm{N}$ at 1300 UTC of 04 April 2015 based on 0600 UTC of 03 April 2015 initial conditions.

In Figure 12, it is found that the model overestimated the average RH of 04 April 2015 by quite a good margin. 


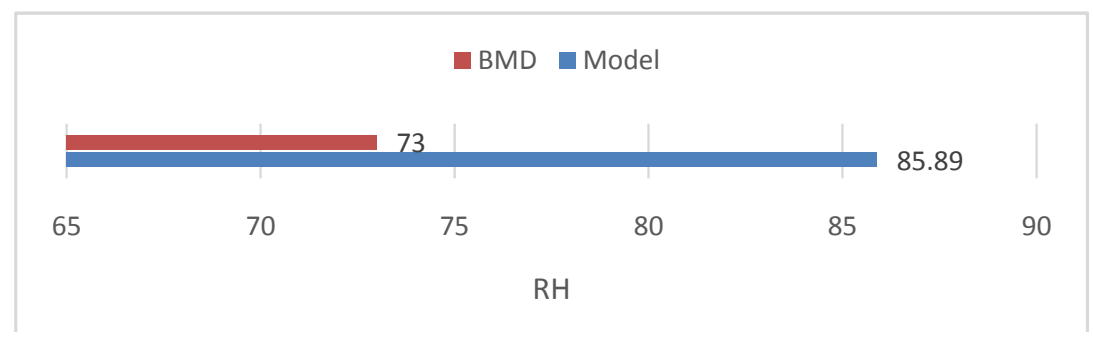

Fig. 12: Comparison of average RH of 04 April 2015.

\subsection{Analysis of Rainfall}

Model-simulated 1-hour rainfall between 1300 UTC and 1400 UTC of 04 April 2015 based on 0600 UTC of 03 April 2015 initial conditions is shown in Figure 13.

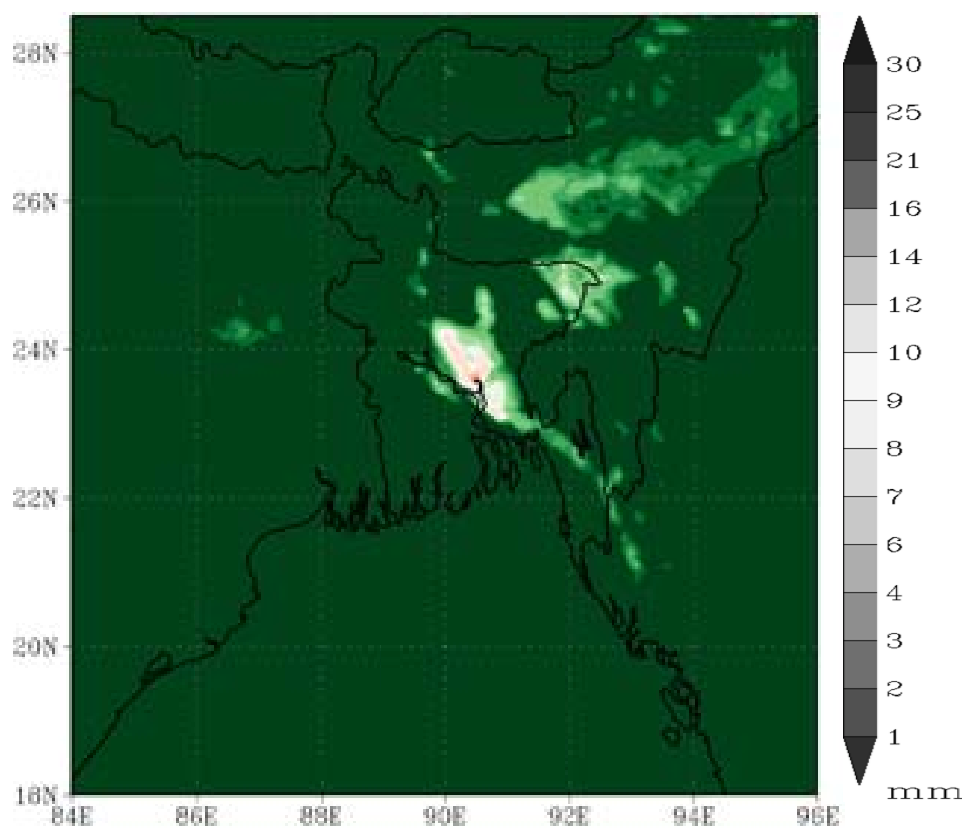

Fig. 13: Model-simulated 1-hour rainfall between 1300 UTC and 1400 UTC of 04 April 2015 based on 0600 UTC of 03 April 2015 initial conditions.

It is seen that the model simulated a rainfall amount of 9-10 $\mathrm{mm}$ over Dhaka and adjoining areas during the one hour from 1300 UTC to 1400 UTC of 04 April 2015. This rainfall can be regarded as a result of the TS occurrence over these areas. For validation, model simulated 24-hour rainfall value of 04 April 2015 is compared with that of BMD observation and TRMM data of NASA. Figure 14 shows this comparison. 


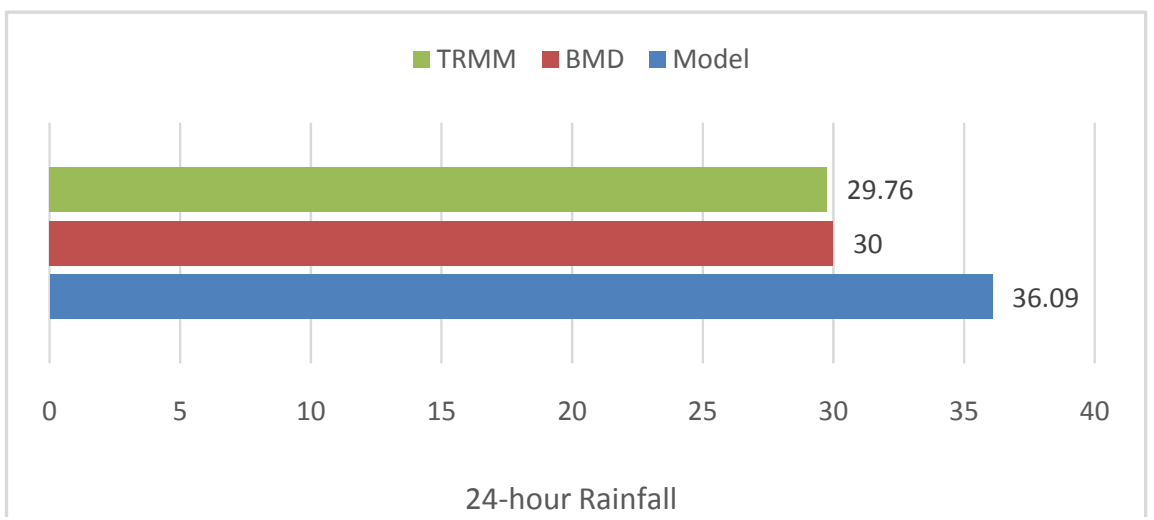

Fig. 14: Comparison of 24-hour rainfall of 04 April 2015 over Dhaka.

It is seen from Figure 14 that the model overestimated both BMD and TRMM data of 24-hour rainfall over Dhaka. The overview of the model-simulated values of the eight parameters along with available observations at 1300 UTC (unless specified otherwise) over Dhaka is given in Table 2.

Table 2: Overview of model-simulated values of different parameters over Dhaka

\begin{tabular}{|l|c|c|c|c|}
\hline \multicolumn{1}{|c|}{ Parameter } & Unit & Simulated value & BMD record & TRMM record \\
\hline MSLP (at 1200 UTC) & $\mathrm{hPa}$ & 1002.88 & 1001.3 & - \\
\hline Wind speed at $850 \mathrm{hPa}$ & $\mathrm{ms}^{-1}$ & 15.02 & - & - \\
\hline Wind speed at $200 \mathrm{hPa}$ & $\mathrm{ms}^{-1}$ & 50.84 & & - \\
\hline Vertical wind shear & $\mathrm{ms}^{-1}$ & 35.82 & & - \\
\hline Vorticity at 500 hPa & $10^{-5} \mathrm{~s}^{-1}$ & 19.21 & - & - \\
\hline Max temperature (24-h) & ${ }^{\circ} \mathrm{C}$ & 34.43 & 34.3 & - \\
\hline Min temperature (24-h) & ${ }^{\circ} \mathrm{C}$ & 24.80 & 24 & - \\
\hline CAPE at 850 hPa & $\mathrm{J} \mathrm{kg}{ }^{-1}$ & 3042 & - & - \\
\hline Average RH (24-h) & $\%$ & 85.89 & 73 & 29.76 \\
\hline Rainfall (24-h) & $\mathrm{mm}$ & 36.09 & 30 & \\
\hline
\end{tabular}

With a careful inspection of Table 2 and the comparisons shown earlier, it can be concluded that the WRF-ARW model performance was quite satisfactory in simulating the thermodynamic features of the TS event of 04 April 2015 over Dhaka. 


\section{Conclusion}

A total of eight parameters regarding the thermodynamic features of the TS event of 4 April 2015 over Dhaka were simulated and analyzed using WRF-ARW model and the simulated values were compared with available observational data to validate the model performance. The comparison reflects the ability of the model to capture the parameters reasonably well despite some spatial and temporal errors. It should be noted that this case study is preliminary in nature and advocates the usefulness of the model in forecasting TS events over Dhaka. But analysis of more number of TS events all over Bangladesh is required before arriving at any comprehensive conclusion.

\section{REFERENCES}

[1] Encyclopedia Britannica Inc. (2017). Thunderstorm. [online] Available at: https://www.britannica. com/science/thunderstorm [Accessed 5th April 2017].

[2] Habib, M. A. (2009). Early Warning System for Severe Thunderstorms in Bangladesh. International Forum on Tornado Disaster Risk Reduction for Bangladesh, Dhaka, Bangladesh.

[3] Vaidya, S. S. (2007). Simulation of weather systems over Indian region using mesoscale models. Meteorol. Atmos. Phys. 95, 15-26.

[4] Chatterjee, P., Pradhan, D. \& De, U. K. (2008). Simulation of hailstorm event using mesoscale model MM5 with modified cloud microphysics scheme. Ann. Geophys. 26, 3545-3555.

[5] Litta, A. J. \& Mohanty, U. C. (2008). Simulation of a severe thunderstorm event during the field experiment of STORM programme 2006 using WRF-NMM model, Current Science, 95 (2), 204-215.

[6] Rajeevan, M., Kesarkar, A., Thampi, S. B., Rao, T. N., Radhakrishna, B. \& Rajasekhar, M. (2010). Sensitivity of WRF cloud microphysics to simulations of severe thunderstorm event over Southeast India. Ann. Geophys. 28, 603-619.

[7] Das, M. K., Chowdhury, M. A. M. \& Das, S. (2015). Sensitivity study with physical parameterization schemes for simulation of mesoscale convective systems associated with squall events, Int. J. Ear. Atmos. Sci. 2 (2), 20-36.

[8] Litta, A. J., Ididcula, S. M., Mohanty, U. C. \& Prasad, S. K. (2012). Comparison of thunderstorm simulations from WRF-NMM and WRF-ARW models over East Indian region, Sci. Wor. J. doi: 10.1100/2012/951870

[9] Ahasan, M. N., Quadir, D. A., Khan, K. A. \& Haque, M. S. (2014). Simulation of a thunderstorm event over Bangladesh using WRF-ARW model, J. Mech. Eng. 44 (2). doi: 10.3329/jme.v44i2.21437

[10] Ahasan, M. N. \& Debsarma, S. K. (2015). Impact of data assimilation in simulation of thunderstorm (squall line) event over Bangladesh using WRF model during SAARC-STORM Pilot Field Experiment 2011, Nat. Haz. 75 (2), 1009-1022.

[11] Skamarock, W. C., Klemp, J. B., Dudhia, J., Gill, D. O., Barker, D. M., Duda, M. G., Huang, X.Y., Wang, W. \& Powers, J. G. (2008). A Description of the Advanced Research WRF Version 3, NCAR Technical Note NCAR/TN-475+STR, p. 113. doi: 10.5065/D68S4MVH

[12] Skamarock, W. C. \& Weisman, M. L. (2009). The impact of positive-definite moisture transport on NWP precipitation forecasts. Mon. Weath. Rev. 137, 488-494.

[13] Ooyama K. V. (1990). A thermodynamic foundation for modeling the moist atmosphere. J. Atmos. Sci., 47, 2580-2593.

[14] Laprise R. (1992). The Euler Equations of motion with hydrostatic pressure as independent variable. Mon. Weath. Rev. 120, 197-207.

[15] American Meteorological Society (2017). Convective available potential energy. Glossary of Meteorology. [online] Available from: https://glossary.ametsoc.org/wiki/Convective _available_ potential_energy [Accessed 2nd February 2017]. 